\title{
DISCOVERING OPTIMUM METHOD TO EXTRACT DEPTH INFORMATION FOR NEARSHORE COASTAL WATERS FROM SENTINEL-2A IMAGERY- CASE STUDY: NAYBAND BAY, IRAN
}

\author{
K. Kabiri ${ }^{\mathrm{a}, *}$ \\ a Department of Marine Remote Sensing, Iranian National Institute for Oceanography and Atmospheric Science, Tehran, Iran
}

kabiri@inio.ac.ir

KEY WORDS: Remote Sensing; Nayband Bay; Bathymetry, Coastal Zone, Persian Gulf

\begin{abstract}
:
The capabilities of Sentinel-2A imagery to determine bathymetric information in shallow coastal waters were examined. In this regard, two Sentinel-2A images (acquired on February and March 2016 in calm weather and relatively low turbidity) were selected from Nayband Bay, located in the northern Persian Gulf. In addition, a precise and accurate bathymetric map for the study area were obtained and used for both calibrating the models and validating the results. Traditional linear and ratio transform techniques, as well as a novel integrated method, were employed to determine depth values. All possible combinations of the three bands (Band 2: blue $(458-523 \mathrm{~nm})$, Band 3: green $(543-578 \mathrm{~nm})$, and Band 4: red $(650-680 \mathrm{~nm})$, spatial resolution: $10 \mathrm{~m})$ have been considered (11 options) using the traditional linear and ratio transform techniques, together with 10 model options for the integrated method. The accuracy of each model was assessed by comparing the determined bathymetric information with field measured values. The correlation coefficients $\left(R^{2}\right)$, and root mean square errors (RMSE) for validation points were calculated for all models and for two satellite images. When compared with the linear transform method, the method employing ratio transformation with a combination of all three bands yielded more accurate results $\left(R^{2}{ }_{M a c}=0.795, R^{2}{ }_{F e b}=0.777, \mathrm{RMSE}_{M a c}=1.889 \mathrm{~m}\right.$, and $\left.\mathrm{RMSE}_{\mathrm{Feb}}=2.039 \mathrm{~m}\right)$. Although most of the integrated transform methods (specifically the method including all bands and band ratios) have yielded the highest accuracy, these increments were not significant, hence the ratio transformation has selected as optimum method.
\end{abstract}

\section{INTRODUCTION}

The Updated and reliable bathymetric information for nearshore coastal waters are essential for coastal management and monitoring, and for mapping benthic habitats in shallow waters (Chust et al., 2010; Kabiri et al., 2013 \& 2014). So far, numerous methods have been developed to measure the depth values and subsequently to produce the bathymetric maps. Among the methods, the most accurate and reliable ones are utilizing the single and multi-beam echo sounders (Maleika et al., 2012; Horta et al., 2014) and airborne LIght Detection And Ranging (LIDAR) (Chust et al., 2010, Saylam et al., 2017), but they are the most expensive techniques as well. A number of lower cost methods, such as vertical beam echo-sounders (VBES), are capable of producing bathymetric maps with acceptable accuracy for coastal research (Sánchez-Carnero et al., 2012).

The potential usefulness of remotely sensed satellite data has been confirmed for mapping and monitoring coastal areas (Moradi and Kabiri, 2015). In this regard, multispectral remotely sensed data have been widely employed to determine depth values in shallow coastal waters. Lyzenga (1978) was the first to develop a method to estimate depth values using multispectral satellite imagery. This method was able to minimize the effect of variation in bottom types on the determined depth values. Stumpf et al. (2003) subsequently proposed a novel ratio transform method that had greater capabilities for estimating depth values in deeper areas and it was less sensitive to different bottom types when compared to the traditional linear transform technique.

The utilization of high spatial resolution imagery $(\sim 2 \mathrm{~m})$ such as QuickBird and WorldView-2 can yield high accuracy and a more detailed bathymetric map (Collin and Planes, 2011; Eugenio et al., 2015, Halls and Costin, 2016); however, these imageries are expensive and can cover a smaller area. By contrast, the medium spatial resolution imageries such as Landsat $(30 \mathrm{~m})$ has been available at no cost since 1985 and can be used to produce reliable and updated medium resolution bathymetric maps (Clark et al., 1987; Baban, 1993; LiceagaCorrea and Euan-Avila, 2002). This capability has been further improved since the launch of Landsat- 8 in February 2013 (Pahlevan et al., 2014; Pacheco et al., 2015; Kabiri and Moradi, 2016; Kabiri, 2017). However, after launching Sentinel-2A satellite on June 2015 with $10 \mathrm{~m}$ spatial resolution, it is expected to observe an improvement in the ability of producing more detailed and precise bathymetric map, where the Sentinel$2 \mathrm{~A}$ includes required spectral bands to determine depth values. To examine this assumption, the main objective of this research is to assess the capability of Sentinel-2A imagery to estimate depth values in near-shore coastal waters. In this regard, Nayband Bay (located in the northern Persian Gulf) was selected as the study area, where an accurate and reliable database from depth values is available for this region. This may enable us to calibrate the different methods for estimation of depth values and to evaluate their accuracies as well. At the first step, the traditional linear and ratio transform methods proposed by Stumpf et al. (2003) were both applied to two selected

\footnotetext{
* Corresponding author
} 
Sentinel-2A images to retrieve depth values in each pixel, by consideration of all possible combinations of bands and band ratios (Band 2: blue (458-523 nm), Band 3: green (543-578 $\mathrm{nm})$, and Band 4: red (650-680 nm), spatial resolution: $10 \mathrm{~m})$. Thereafter, a novel method was proposed that combined the linear and ratio transform methods. This new method was then tested to determine whether it would improve the estimated depth values or not. The optimum method was then selected by comparing the statistical indicators, such as RMSE and $R^{2}$ for the retrieved depth values obtained by applying all abovementioned methods. The estimated results were subsequently compared to the field measured data. The flexibility and robustness of the methods were then evaluated by assessing the estimated depth values from all three methods for different depth values.

\section{MATERIALS AND METHODS}

\subsection{Study Area}

The selected study area was Nayband Bay (Fig. 1a), which is located in the south of Iran (north of the Persian Gulf), between latitudes $27^{\circ} 23^{\prime} \mathrm{N}-27^{\circ} 30^{\prime} \mathrm{N}$ and longitudes $52^{\circ} 35^{\prime} \mathrm{E}-52^{\circ} 41^{\prime}$ E (Fig. 1b). The total area of this bay is $\sim 70 \mathrm{~km}^{2}$ and the perimeter is $\sim 40 \mathrm{~km}$. The areas with greater depths $(\sim 20 \mathrm{~m})$ are happened in the western parts, while the central parts have depths of $\sim 10 \mathrm{~m}$. The climate of this area categorizes as tropical, where monthly mean air temperatures fluctuate between $16^{\circ} \mathrm{C}$ (January) and $35^{\circ} \mathrm{C}$ (July) during a year. The water type of bay categorizes as Case II which means has relatively higher turbidity in comparison with Open Ocean waters (Case I). Our regular field observations in the study area showed that usually the amount of water turbidity in summertime is higher than wintertime.

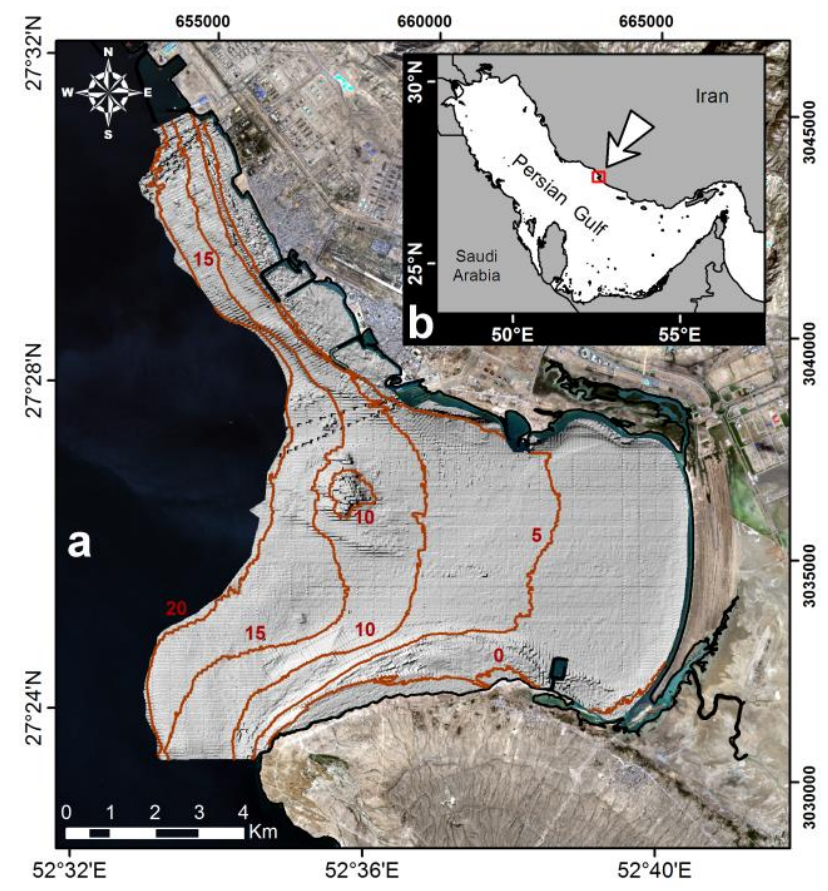

Figure 1. Bathymetric map of the study area (Nayband Bay), where XY refers to the UTM-Zone 39 (WGS-84) projection system (a). Location of Nayband Bay in the south of Iran (b)

\subsection{Remotely Sensed Data}

Two Sentinel-2A satellite images were downloaded from the USGS (United States Geological Survey) EarthExplorer portal (https://earthexplorer.usgs.gov/). This portal has provided a wide range of global remotely sensed data, most of which (including Sentile-2A imagery) are freely available for downloading. Two cloud-free images of the study area were selected. The images acquired on February 15, 2016 and March 03, 2016 and they were downloaded in the format of a Level-1 GeoTIFF data product. Table 1 summarizes the information about the satellite images selected for this study.

\begin{tabular}{|l|l|}
\hline Sentinel-2A Entity ID & $20160215 T 072839$ \\
\hline Acquisition Start Date & $2016-02-15 T 07: 18: 40.591 Z$ \\
Acquisition End Date & $2016-02-15 T 07: 28: 39.481 \mathrm{Z}$ \\
Cloud Coverage (\%) & 0.0021 \\
\hline Sentinel-2A Entity ID & $20160303 \mathrm{~T} 071558$ \\
\hline Acquisition Start Date & $2016-03-03 \mathrm{~T} 07: 05: 38.253 \mathrm{Z}$ \\
Acquisition End Date & $2016-03-03 \mathrm{~T} 07: 15: 58.790 \mathrm{Z}$ \\
Cloud Coverage (\%) & 0.5884 \\
\hline Tile Number & T39RXL \\
Datum, Map Projection & WGS84, UTM, 39N \\
Spatial Resolution & 10 m (for R, G, B bands) \\
Scene Centre & $27^{\circ} 31^{\prime} 15.511^{\prime N}, 52^{\circ} 34^{\prime} 06.36 " \mathrm{E}$ \\
\hline
\end{tabular}

Table 1. The detailed information of two Sentinel-2A images used for this study

(Source: USGS, https://earthexplorer.usgs.gov/)

The raw satellite images required some corrections during the pre-processing steps before they could be used for further processes. These pre-processes include radiometric, atmospheric, and geometric corrections. The required coefficients are provided by the ESA in a metadata file (XML file) that can be found together with other files. Specifically for this study, image processing analysis was performed using ENVI $^{\circledR} 5.3$ software. This software has some special modules for importing, displaying, and analysing Sentinel-2A imagery based on the aforesaid metadata file. The first step was to convert the raw digital numbers (DN values) to radiance values. Subsequently, the fast line-of-sight atmospheric analysis of hypercubes $\left(\right.$ FLAASH $^{\circledR}$ ) module was used to perform atmospheric correction. The atmospheric model was selected as tropical, and the aerosol model was indicated as maritime, because it was aimed to analyse the image data in a marine area. Other required settings, such as sensor type, sensor altitude, ground elevation, flight time, and initial visibility, were selected based on other existing metadata, data, and previous knowledge about the study area. The output of this step is atmospherically corrected reflectance values for each pixel of the Sentinel-2A image. The original satellite images are geo-registered and provided in the universal transverse Mercator (UTM) projection, but they must be re-corrected based on existing accurate ground control points (GCPs) to increase the precision of the geo-locations. In doing so, the existing map (scale= $1: 1,000)$ was used for geo-referencing the both satellite images and minimizing the geometric errors. 


\subsection{Field Measured Bathymetric Records}

A hydrographic field survey was conducted by the National Cartographic Center of Iran (NCC) in 2013 to produce a nautical chart of Nayband Bay. Point-wise depth data (Fig. 2) were collected using a single beam echo-sounder coupled with a differential global positioning system (DGPS), so that the accuracy and precision of data are acceptable to generate bathymetric maps at a scale of 1:1,000 or smaller. According to the metadata of the map, the depth values of the surveyed points are reduced to a chart datum with approximately the level of the lowest astronomical tide. In this study, the original sounding points were acquired and employed for statistical analysis. All depth values were adjusted according to tidal information from the study area (obtained from NCC, Department of Hydrography) for the date and time of the satellite overpasses. Subsequently, in order to perform a comparative analysis, the point-wise bathymetric data were converted to a raster grid format, in accordance with geometric properties (coordinate system and pixel size) of the selected Sentinel-2A images. It should be noted that there is a $\sim 3$ year time interval between the field measurements and the date of the satellite imaging; hence, the bathymetry of the area may have changed during this period. However, our field measurements in Nayband Bay showed that the effect of this variation in our computations is minor, as it was infrequently greater than $0.5 \mathrm{~m}$.

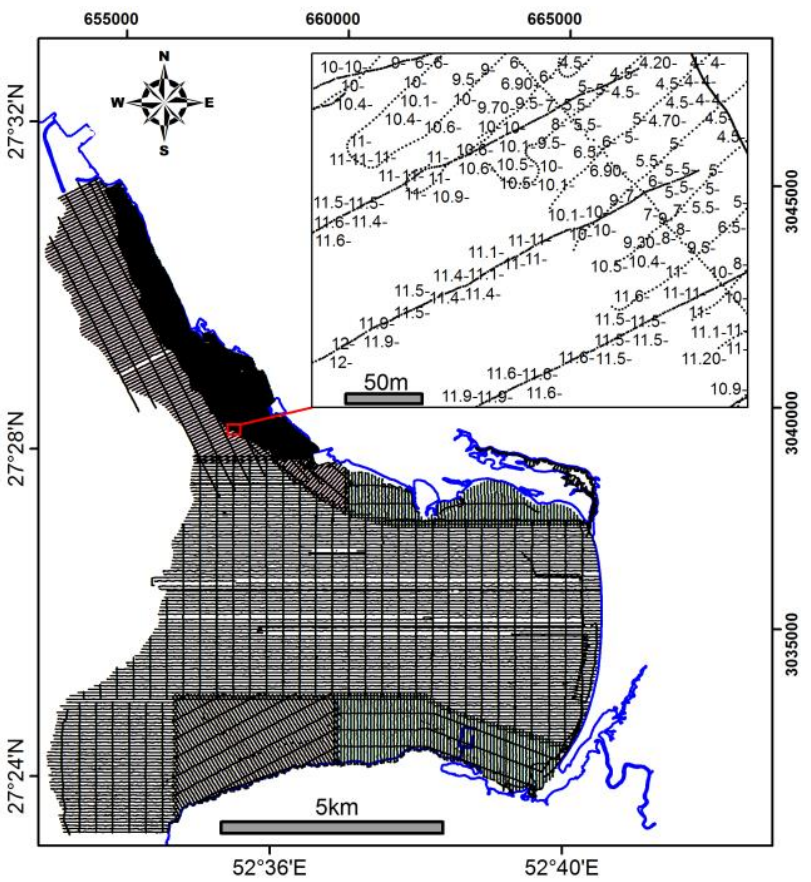

Figure 2. Original sounding points surveyed using single beam echo-sounder by the National Cartographic Centre of Iran. The density of points is higher in areas with rough topography and lower in smooth topography areas

\subsection{Retrieving Depth Values from Multispectral Bands}

The methodology for extraction of depth values from multispectral satellite images initialized by Lyzenga (1978, 1981) and then developed by Stumpf et al. (2003) satellite images with higher spatial resolution. Stumpf et al. (2003) recommended a novel method, called ratio transform to retrieve depth values from multi bands which differed from the traditional linear transform algorithm suggested by Lyzenga (1978, 1985). In this study, the accuracy of both algorithms where assessed using all possible combinations of three visible bands of Sentinel-2A imagery [Band 2, Blue: $490 \mathrm{~nm}$ (B), Band 3, Green: $560 \mathrm{~nm}(\mathrm{G})$, and Band 4, Red: $665 \mathrm{~nm}(\mathrm{R})$ ] with $10 \mathrm{~m}$ spatial resolution.

\subsubsection{Linear Transform Method}

Based on this methodology, the depth $(Z)$ values can be determined by applying Eq. 1 (Lyzenga, 1978, 1985)

where

$$
Z=a_{0}+a_{1} X_{i}+a_{2} X_{j}+a_{a} X_{k}
$$

$$
X_{i}=\ln \left[R_{w}\left(\lambda_{i}\right)-R_{m o}\left(\lambda_{i}\right)\right]
$$

The $X_{j}$, and $X_{k}$ values may be determined using equations similar to Eq. 2. In Eqs. 1 and 2, $R_{w}$ is the reflectance values of water (which includes the bottom reflectance in optically shallow waters), $R_{\infty}$ is the reflectance value of optically deep water (water column reflectance), and $\lambda_{i}$ is the $i^{\text {th }}$ spectral band, whereas the constant $a$ values ( $a_{0}$ to $a_{n}$, where $n$ is numbers of spectral bands) should be determined (usually using multiple linear regression). In the first step, the $R_{\infty}$ values for all three bands ( $R, G$, and $B$ bands) are computed by plotting the reflectance values of all pixels within the study area versus the referenced depth values (Fig. 3). According to the plots, the minimum recorded reflectance values are $0.2,0.4$, and 0.6 for $\mathrm{R}, \mathrm{G}$, and $\mathrm{B}$ bands, and are considered as $R_{\infty}{ }^{R}, R_{\infty}{ }^{G}$, and $R_{\infty}{ }^{B}$, respectively. To convert reflectances to the form of percentage values, they were multiplied by 100 . Four possible combinations of these bands, including: i) R, G, B; ii) R, G; iii) $\mathrm{R}, \mathrm{B}$; and iv) $\mathrm{B}, \mathrm{G}$ were used to determine the $Z$ values. The plots in Fig. 3 show no light penetration ability for any of the three bands at depths of more than $15 \mathrm{~m}$; hence, the pixels with depths of more than $15 \mathrm{~m}$ were eliminated from computations.

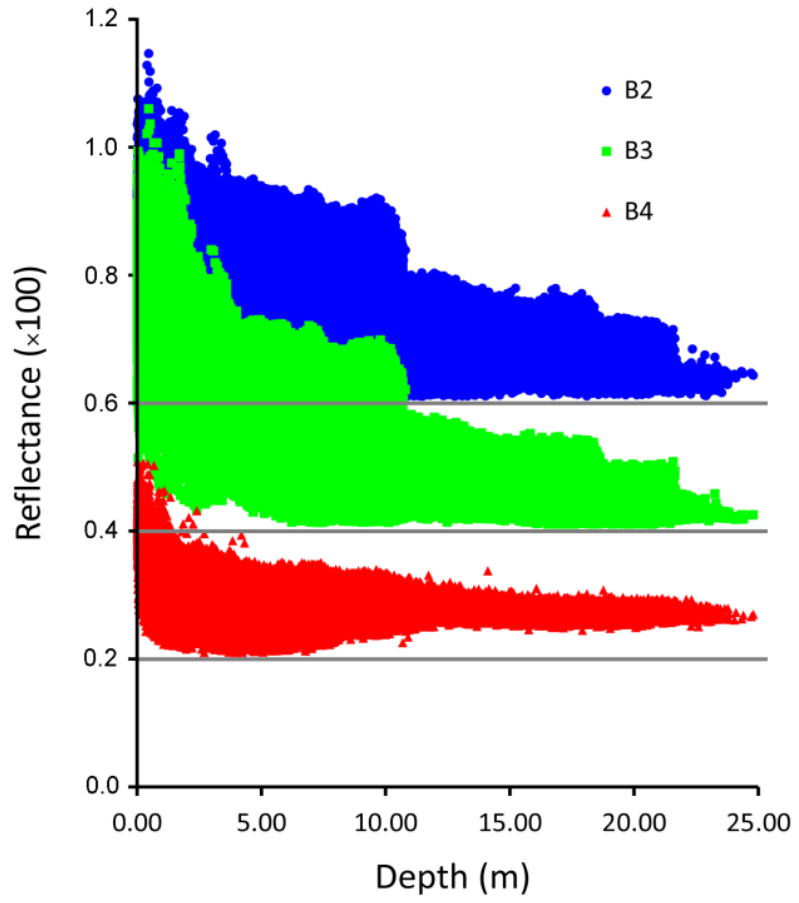

Figure 3. Scaled reflectance values of blue, green, and red bands versus depth values in all pixels of the satellite image of the study area 
Furthermore, any pixels consisting of noisy objects (usually clouds and boats, and the very shallow areas) were also filtered out (Fig. 4b). After the exclusion of these points, the total number of remaining pixels was $\sim 131000$. One half of these points was used for calibration of the models (determination of unknown parameters), and the other half was used for validating the results. Thus, $\sim 65500$ pixels (the blue pixels in Fig. 4a) were randomly selected for use in multiple linear regressions for determining the unknown $a_{i}$ parameters, and the other $\sim 65500$ pixels (the red pixels in Fig. 4a) were considered for validating the results.

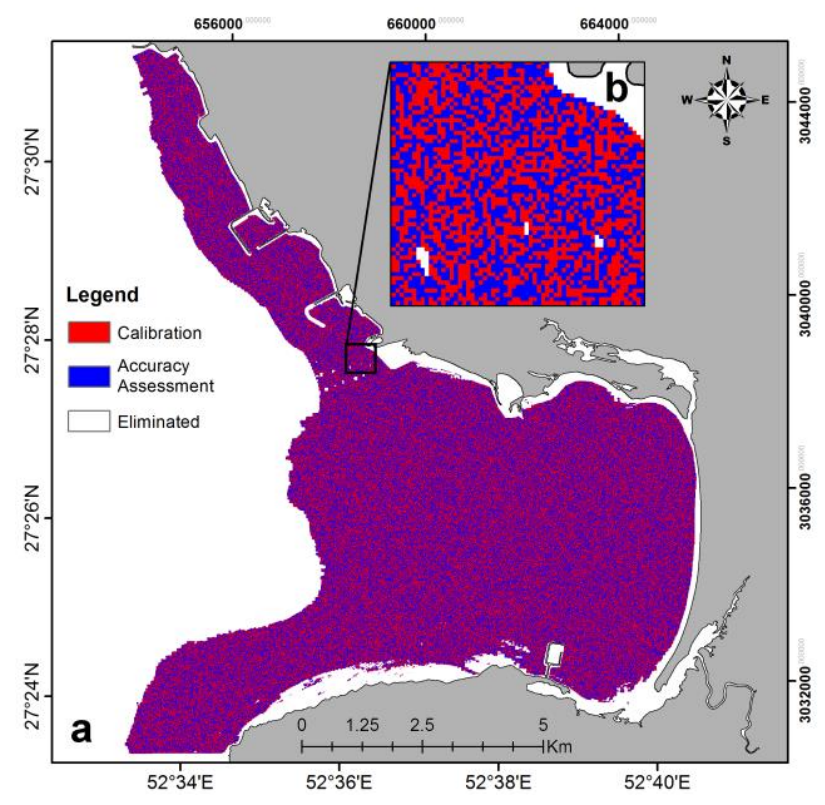

Figure 4. Randomly selected pixels for calibration of the models (blue pixels) and validation of the results (red pixels). The white pixels indicate very shallow coastal areas, clouds or other nondesired points that have been eliminated from computations

In the following, the multiple linear regression model was used to determine unknown parameters.

\subsubsection{Ratio Transform Method}

In comparison with the linear transform methodology, the ratio transform method has been developed to be more robust over variable sea bottom types (Stumpf et al., 2003). The original proposed methodology was based on the ratio values of two bands (usually the $\mathrm{B}$ and $\mathrm{G}$ bands). In this research, the formulation was expanded to consider all three chosen bands of Sentinel-2A imagery. According to this consideration, the depth values can be calculated by applying Eq. 3 .

$$
\begin{array}{r}
Z=-m_{0}+m_{1} \frac{\ln \left(n R_{w}\left(\lambda_{B}\right)\right)}{\ln \left(n R_{w}\left(\lambda_{G}\right)\right)} \\
+m_{2} \frac{\ln \left(n R_{w}\left(\lambda_{B}\right)\right)}{\ln \left(n R_{w}\left(\lambda_{R}\right)\right)}+m_{a} \frac{\ln \left(n R_{w}\left(\lambda_{G}\right)\right)}{\ln \left(n R_{w}\left(\lambda_{R}\right)\right)}
\end{array}
$$

where $m_{l}-m_{3}$ are tunable constants to scale the ratio to depth, $n$ is a fixed constant for all areas $(n=100)$, and $m_{0}$ is the offset for a depth of $0 \mathrm{~m}$. Similar to the linear transform method, the values of unknown $m_{i}$ parameters were determined by applying multiple linear regression. However, since $Z$ values can be determined by applying only one ratio formed by applying only two bands, the total number of possible combinations of band ratios is 7, including: i) $\mathrm{B} / \mathrm{G}, \mathrm{B} / \mathrm{R}, \mathrm{G} / \mathrm{R}$; ii) $\mathrm{B} / \mathrm{G}, \mathrm{B} / \mathrm{R}$; iii) $\mathrm{B} / \mathrm{G}$, $\mathrm{G} / \mathrm{R}$; iv) $\mathrm{B} / \mathrm{R}, \mathrm{G} / \mathrm{R}$; v) $\mathrm{B} / \mathrm{G}$; vi) $\mathrm{B} / \mathrm{R}$; and vii) $\mathrm{G} / \mathrm{R}$. Finally, the depth values for all selected pixels used for validation of the results (the same points used in the previous method) were calculated using Eq. 3 and using the calculated $m_{i}$ parameters.

\subsubsection{Integrated transform method}

The probable improvement in precision and accuracy of the determined depth values was examined by developing an overall model based on integration of the two abovementioned transforms (Eq. 4). Similar to the linear and ratio transform methods, the unknown parameters were calculated by applying linear regression on the 10 selected integrated models. These models were selected based on the results obtained from previous analysis by combining highly correlated bands/band ratios with depth values. The results obtained from these models were compared with the linear and ratio transform methods, and the three statistical indices were determined for these 10 models as well.

$$
\begin{gathered}
Z=b_{0}+b_{1} X_{B}+b_{2} X_{G}+b_{a} X_{R} \\
+b_{4} \frac{\operatorname{In}\left(n R_{W}\left(a_{B}\right)\right)}{\ln \left(n R_{W}\left(a_{C}\right)\right)}+b_{5} \frac{\operatorname{In}\left(n R_{W}\left(a_{B}\right)\right)}{\operatorname{In}\left(n R_{W}\left(\lambda_{R}\right)\right)}+b_{6} \frac{\operatorname{In}\left(n R_{W}\left(a_{G}\right)\right)}{\operatorname{In}\left(n R_{W}\left(a_{R}\right)\right)}
\end{gathered}
$$

\section{RESULTS AND DISCUSSION}

Table 2 summarizes the determined values for $a_{i}, m_{i}$, and $b_{i}$ parameters for all 21 possible combinations of bands/band ratios in the linear, ratio, and integrated transform methods. The two statistical indicators $\left(R^{2}\right.$ and RMSE for the points used for validation) for both satellite images are represented. The depth values for all pixels selected for validation were determined using the determined values for unknown parameters and for all 21 chosen models.

Particularly for the linear transform method, the results showed the highest accuracy when all three bands were applied, and the statistical indicators reflected this fact. By contrast, the lowest accuracy was observed when utilizing the $\mathrm{B}$ and $\mathrm{R}$ bands together. Other combination of $\mathrm{B}$ and $\mathrm{G}$ bands gave slightly less accurate results than those obtained using all three bands; however, this decrease may be negligible. This means that although adding $\mathrm{R}$ band to the computations may increase the final accuracy, this increment is negligible. However, in comparison with linear transform models, the results acquired from the ratio transform models gave the better accuracy when all three bands were applied (option 5). Here, the lowest accuracy was obtained for the two B, R bands. On the other hand, the results achieved for the integrated transform method demonstrated an increasing in the accuracy of the estimated depth values when compared with the linear and ratio transform methods. However, this increment was not noticeable in all 10 selected models, (Table 2), particularly in comparison with the option 5 when all bands incorporated in ratio transform method. However, among the selected band/band ratio combinations in this method, options 12 and 19 had higher accuracies. 


\begin{tabular}{|c|c|c|c|c|c|c|c|c|c|c|c|c|}
\hline \multicolumn{13}{|c|}{ Linear transform } \\
\hline No. & Bands/Band Ratios & $a_{0}$ & $a_{1}$ & $a_{2}$ & $a_{3}$ & & & & $R^{2} \mathrm{Mac}$ & $\begin{array}{c}R M S E_{M a c} \\
(\mathrm{~m})\end{array}$ & $R^{2} \mathrm{Feb}$ & $\begin{array}{c}R M S E_{F e b} \\
(\mathrm{~m})\end{array}$ \\
\hline 1 & $\mathrm{~B}, \mathrm{G}, \mathrm{R}$ & 16.126 & 5.273 & -9.921 & 1.478 & & & & 0.740 & 2.126 & 0.702 & 2.362 \\
\hline 2 & G,R & 14.786 & & -6.024 & 3.547 & & & & 0.661 & 2.427 & 0.742 & 2.207 \\
\hline 3 & $B, R$ & 16.582 & -4.296 & & 0.565 & & & & 0.389 & 3.265 & 0.648 & 2.639 \\
\hline 4 & $B, G$ & 18.056 & 5.737 & -9.838 & & & & & 0.736 & 2.142 & 0.655 & 2.488 \\
\hline \multicolumn{13}{|c|}{ Ratio transform } \\
\hline & & $m_{0}$ & $m_{1}$ & $m_{2}$ & $m_{3}$ & & & & & & & \\
\hline 5 & $\mathrm{~B} / \mathrm{G}, \mathrm{B} / \mathrm{R}, \mathrm{G} / \mathrm{R}$ & -1415.12 & 1357.24 & -1025.1 & 1070.49 & & & & 0.795 & 1.889 & 0.777 & 2.039 \\
\hline 6 & $\mathrm{~B} / \mathrm{G}, \mathrm{B} / \mathrm{R}$ & -148.04 & 161.066 & -14.02 & & & & & 0.761 & 2.040 & 0.678 & 2.398 \\
\hline 7 & B/G,G/R & -133.74 & 146.045 & & -13.504 & & & & 0.760 & 2.043 & 0.672 & 2.425 \\
\hline 8 & $\mathrm{~B} / \mathrm{R}, \mathrm{G} / \mathrm{R}$ & 22.671 & & 121.12 & -143.16 & & & & 0.751 & 2.081 & 0.656 & 2.505 \\
\hline 9 & $\mathrm{~B} / \mathrm{G}$ & -166.97 & 161.822 & & & & & & 0.756 & 2.060 & 0.618 & 2.655 \\
\hline 10 & $\mathrm{~B} / \mathrm{R}$ & 36.215 & & -23.45 & & & & & 0.014 & 4.141 & 0.015 & 4.179 \\
\hline 11 & $\mathrm{G} / \mathrm{R}$ & 115.48 & & & -91.605 & & & & 0.524 & 2.876 & 0.325 & 3.956 \\
\hline \multicolumn{13}{|c|}{ Integrated transform } \\
\hline & & $b_{0}$ & $b_{1}$ & $b_{2}$ & $b_{3}$ & $b_{4}$ & $b_{5}$ & $b_{6}$ & & & & \\
\hline 12 & $\mathrm{~B}, \mathrm{G}, \mathrm{R}, \mathrm{B} / \mathrm{G}, \mathrm{B} / \mathrm{R}, \mathrm{G} / \mathrm{R}$ & -2178.9 & -1.264 & 4.147 & -1.653 & 2095.284 & -1605.6 & 1666.153 & 0.801 & 1.860 & 0.706 & 2.271 \\
\hline 13 & $\mathrm{~B}, \mathrm{G}, \mathrm{R}, \mathrm{B} / \mathrm{G}, \mathrm{G} / \mathrm{R}$ & -180.08 & -0.205 & -2.66 & 4.007 & 146.016 & & 24.298 & 0.771 & 1.995 & 0.639 & 2.531 \\
\hline 14 & $\mathrm{~B}, \mathrm{G}, \mathrm{R}, \mathrm{B} / \mathrm{R}, \mathrm{G} / \mathrm{R}$ & -19.840 & 0.422 & -3.55 & 3.682 & & 107.71 & -93.000 & 0.770 & 2.013 & 0.633 & 2.555 \\
\hline 15 & $\mathrm{~B}, \mathrm{G}, \mathrm{R}, \mathrm{B} / \mathrm{G}, \mathrm{B} / \mathrm{R}$ & -141.27 & 0.087 & -2.72 & 3.363 & 117.725 & 16.685 & & 0.770 & 1.998 & 0.651 & 2.485 \\
\hline 16 & $\mathrm{~B}, \mathrm{~B} / \mathrm{G}, \mathrm{B} / \mathrm{R}, \mathrm{G} / \mathrm{R}$ & -1610.83 & 0.524 & & & 1542.891 & -1175.54 & 1227.843 & 0.797 & 1.878 & 0.757 & 2.132 \\
\hline 17 & $\mathrm{G}, \mathrm{B} / \mathrm{G}, \mathrm{B} / \mathrm{R}, \mathrm{G} / \mathrm{R}$ & -1812.49 & & 1.12 & & 1732.744 & -1320.37 & 1380.095 & 0.799 & 1.871 & 0.740 & 2.181 \\
\hline 18 & $\mathrm{R}, \mathrm{B} / \mathrm{G}, \mathrm{B} / \mathrm{R}, \mathrm{G} / \mathrm{R}$ & -1565.74 & & & 1.070 & 1487.905 & -1120.71 & 1179.866 & 0.797 & 1.880 & 0.760 & 2.117 \\
\hline 19 & $\mathrm{~B}, \mathrm{G}, \mathrm{B} / \mathrm{G}, \mathrm{B} / \mathrm{R}, \mathrm{G} / \mathrm{R}$ & -2090.87 & -1.72 & 3.72 & & 1993.449 & -1510.64 & 1580.985 & 0.801 & 1.862 & 0.727 & 2.201 \\
\hline 20 & $\mathrm{~B}, \mathrm{R}, \mathrm{B} / \mathrm{G}, \mathrm{B} / \mathrm{R}, \mathrm{G} / \mathrm{R}$ & -1612.24 & 0.554 & & -0.069 & 1545.016 & -1177.93 & 1229.733 & 0.797 & 1.878 & 0.756 & 2.132 \\
\hline 21 & $\mathrm{G}, \mathrm{R}, \mathrm{B} / \mathrm{G}, \mathrm{B} / \mathrm{R}, \mathrm{G} / \mathrm{R}$ & -2082.48 & & 2.98 & -2.754 & 2017.885 & -1562.86 & 1610.973 & 0.800 & 1.864 & 0.694 & 2.316 \\
\hline
\end{tabular}

Table 2. Determined parameters for all combinations of bands/band ratios for linear, ratio, and integrated transform methods

According to the previous studies, a high degree of turbidity is considered the most undesirable parameter for retrieving bathymetric data from multispectral imagery (Pacheco et al., 2015, Kabiri, 2017). Typically, this parameter has higher values in coastal waters (Case II) than in open oceans (Case I) due to the highly colored dissolved organic matter (CDOM) transported by river and estuary systems (Moore et al., 1999) and other suspended particles. Conversely, the estimated depth values are expected to be less accurate in deeper areas than in shallower areas due to the attenuation of light in all bands during as it passes through the water column. To assess that which model is less sensitive to the variation of depth values, the RMSE values was computed in different depth levels including depths $<2 \mathrm{~m}, 2-4 \mathrm{~m}, 4-8 \mathrm{~m}$, and $>8 \mathrm{~m}$ (Fig 5). As seen in Fig 5, the best results obtained for the depth range between 2 and 4 meter. This means that although with increasing the depth values the accuracy of the models will be decreased, the extremely shallow waters $(<2 \mathrm{~m})$ may decrease the efficiency of the models as well, due to the high water turbidity.

\section{CONCLUSION AND SUMMARY}

The Sentinel-2A launched on June 2015 differs somewhat from previous similar satellite imagery. The present study attempted to inspect the three different methodologies to extract depth values from three visible bands (red, green, and blue) of Sentinel-2A imagery. In doing so, linear regression, coupled with field measured data, was used to determine the unknown parameters of 21 model options for formerly developed linear and ratio transform methodologies (Lyzenga 1978, 1985; Stumpf et al., 2003), as well as for a novel integrated method. Consequently, the statistical indicators demonstrated that the ratio transform method including all three bands has more proficiency in determining the depth values in coastal water bodies with a high variation in bottom types, whereas using the linear transform methods may lead to less accurate results.
However, the final results showed that the integrated models proposed in this study have higher accuracy than the conventional linear and ratio transform models, yet this improvement is not major. Additionally, most of models had higher accuracy in the areas with depth between 2 and 4 meter, where the effects of water turbidity and attenuation of light in water column on bottom reflectance values are minimal.

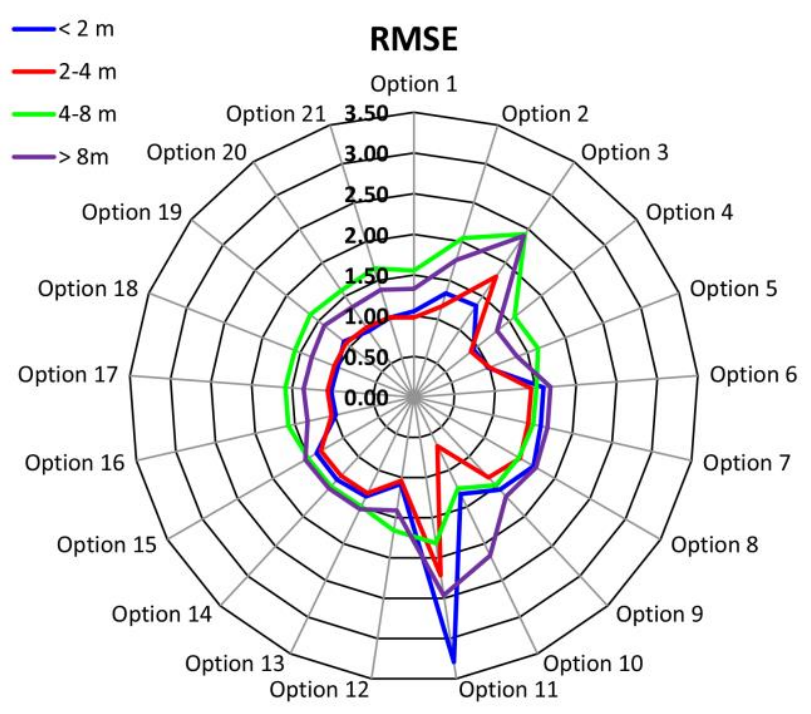

Figure 5. Computed RMSE values for all 21 model options in different depth levels 


\section{REFERENCES}

Baban SM (1993) The evaluation of different algorithms for bathymetric charting of lakes using Landsat imagery. International Journal of Remote Sensing 14:2263-2273

Chust G, Grande M, Galparsoro I, Uriarte A, Borja A (2010) Capabilities of the bathymetric Hawk Eye LiDAR for coastal habitat mapping: a case study within a Basque estuary. Estuarine, Coastal and Shelf Science 89:200-213

Clark RK, Fay TH, Walker CL (1987) Bathymetry calculations with Landsat 4 TM imagery under a generalized ratio assumption. DTIC Document.

Collin A, Planes S (2011) What is the value added of 4 bands within the submetric remote sensing of tropical coastscape? Quickbird-2 vs WorldView-2. 2165-2168 in Geoscience and Remote Sensing Symposium (IGARSS), 2011 IEEE International

Eugenio F, Marcello J, Martin J (2015) High-resolution maps of bathymetry and benthic habitats in shallow-water environments using multispectral remote sensing imagery. IEEE Transactions on Geoscience and Remote Sensing 53(7): 3539-3549

Halls J, Costin K (2016) Submerged and Emergent Land Cover and Bathymetric Mapping of Estuarine Habitats Using WorldView-2 and LiDAR Imagery. Remote Sensing 8(9), 718

Horta J, Pacheco A, Moura D, Ferreira Ó (2014) Can recreational echosounder-chartplotter systems be used to perform accurate nearshore bathymetric surveys? Ocean Dynamics 64:1555-1567

Kabiri K, Pradhan B, Samimi-Namin K, Moradi M (2013) Detecting coral bleaching using QuickBird multi-temporal data: a feasibility study at Kish Island, the Persian Gulf. Estuarine, Coastal and Shelf Science 117:273-281

Kabiri K, Rezai H, Moradi M, Pourjomeh F (2014) Coral reefs mapping using parasailing aerial photography-feasibility study: Kish Island, Persian Gulf. Journal of coastal conservation 18(6): 691-699

Kabiri K, Moradi M (2016) Landsat-8 imagery to estimate clarity in near-shore coastal waters: Feasibility study-Chabahar Bay, Iran. Continental Shelf Research 125: 44-53

Kabiri K (2017) Accuracy assessment of near-shore bathymetry information retrieved from Landsat- 8 imagery. Earth Science Informatics; In press, doi: 10.1007/s12145-017-0293-7

Liceaga-Correa M, Euan-Avila J (2002) Assessment of coral reef bathymetric mapping using visible Landsat Thematic Mapper data. International Journal of Remote Sensing 23:3-14

Lyzenga DR (1978) Passive remote sensing techniques for mapping water depth and bottom features. Applied optics $17: 379-383$

Lyzenga DR (1981) Remote sensing of bottom reflectance and water attenuation parameters in shallow water using aircraft and Landsat data. International Journal of Remote Sensing 2:71-82
Lyzenga DR (1985) Shallow-water bathymetry using combined lidar and passive multispectral scanner data. International Journal of Remote Sensing 6:115-125

Maleika W, Palczynski M, Frejlichowski D (2012) Interpolation methods and the accuracy of bathymetric seabed models based on multibeam echosounder data. 466-475 Intelligent information and database systems. Springer.

Moore WS (1999) The subterranean estuary: a reaction zone of ground water and sea water. Marine Chemistry 65:111-125

Moradi M, Kabiri K (2015) Spatio-temporal variability of SST and Chlorophyll-a from MODIS data in the Persian Gulf. Marine Pollution Bulletin 98(1): 14-25

Pacheco A, Horta J, Loureiro C, Ferreira Ó (2015) Retrieval of nearshore bathymetry from Landsat 8 images: A tool for coastal monitoring in shallow waters. Remote Sensing of Environment 159:102-116

Pahlevan N, Lee Z, Wei J, Schaaf CB, Schott JR, Berk A (2014) On-orbit radiometric characterization of OLI (Landsat-8) for applications in aquatic remote sensing. Remote Sensing of Environment 154:272-284

Sánchez-Carnero N, Rodríguez-Pérez D, Couñago E, Aceña A, Freire J (2012) Using vertical Sidescan Sonar as a tool for seagrass cartography. Estuarine, Coastal and Shelf Science 115:334-344

Saylam K, Brown RA, Hupp JR (2017) Assessment of depth and turbidity with airborne Lidar bathymetry and multiband satellite imagery in shallow water bodies of the Alaskan North

Slope. International Journal of Applied Earth Observation and Geoinformation, 58:191-200

Stumpf RP, Holderied K, Sinclair M (2003) Determination of water depth with high-resolution satellite imagery over variable bottom types. Limnology and Oceanography 48:547-556 